\title{
Auf dem RadiologieKongressRuhr haben Sie die gesamte Radiologie im Blick!
}

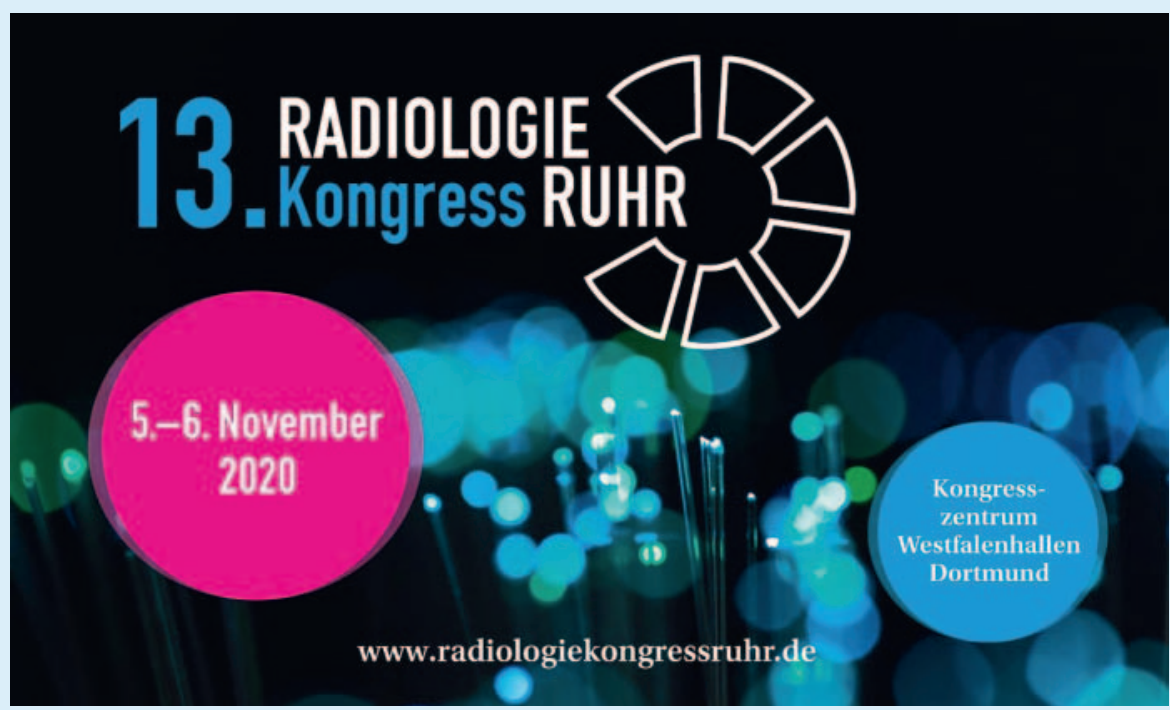

Sehr geehrte Damen und Herren,

fußballbegeisterte Region, innovative Smart City, modernes Zentrum der Radiologie: Das im Metropolraum Rhein-Ruhr gelegene Dortmund präsentiert sich in vielen Facetten.

Vom 5. bis 6. November 2020 stehen die Westfalenhallen Dortmund wieder ganz im Zeichen des RadiologieKongressRuhr (RKR) und bilden für 2 Tage den regionalen Fokus des radiologischen Austauschs - mit vielen Gelegenheiten für Gespräche und fachliche Diskussionen im einladenden Ambiente des modernen Kongresszentrums.

Auch 2020 ist es unser Ziel, das große Spektrum der Radiologie umfänglich abzubilden.
Das breit aufgestellte Fortbildungsprogramm liefert anhand organbezogener Themenblöcke Grundlagen- und Spezialwissen in Diagnostik und Therapie. Den Auftakt zu 2 spannenden Kongresstagen markieren eine Sitzung zur muskuloskelettalen Radiologie und zur Mammadiagnostik. Weitere Schwerpunkte sind die Thorax- und Lungenbildgebung sowie die Interventionelle Radiologie.

Was letztes Jahr als erfolgreiches neues Format startete, führen wir auch in diesem Jahr weiter: „Meine schönsten Fehler“. Seien Sie gespannt, wenn Expertinnen und Experten über ihre lehrreichsten Fälle aus der Interventionellen Radiologie und bildgebenden Diagnostik berichten. Neben der Theorie liefern Simulator-Kurse in den Modulen
$A-D$ und E-F sowie im Format „Flinke Finger “ ein praxisnahes Training für die Interventionelle Radiologie.

Auch für die MTRA haben wir einen abwechslungsreichen Fortbildungstag geplant: So werden die Teilnehmerinnen und Teilnehmer genauestens über aktuelle Themen wie Kontrastmittel, Strahlenschutz und Lungenscreening informiert.

Ein neues Format erwartet Sie im Rahmen der Industrieausstellung: In kurzen Vorträgen - den „Power Pitches“ - stellen Vertreter von großen Unternehmen, aber auch von Start-ups, ihre technischen Innovationen vor. In einer offenen Runde können Sie hier miteinander ins Gespräch kommen.

Seien auch Sie Teil der 13. Ausgabe des RKR im Herzen des Ruhrgebiets und nehmen Sie mit uns die gesamte Radiologie in den Blick!

Mit den besten Grüßen

Ihr Prof. Dr. Stefan Rohde

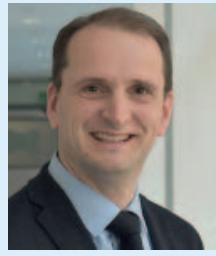

Prof. Dr. Stefan Rohde 